\title{
Entrevista: Sylvia Leser de Mello
}

\begin{abstract}
Nesta entrevista, realizada no dia 23 de março de 1998, a professora Sylvia Leser de Mello nos fala um pouco sobre as mudanças que tem percebido na atuação profissional do psicólogo e sobre sua concep̧ção de psicologia. Salienta a importância da psicologia social para a formação desse profissional e reflete sobre a centralidade da categoria trabalho para a compreensão do sujeito e do processo de construção de sua identidade.
\end{abstract}

Leny Sato - Sylvia, você realizou um estudo sobre o perfil do psicólogo ${ }^{11}$, publicado em 1975. Você identifica mudanças no perfil do psicólogo, comparando-se o que você encontrou naquela época e o perfil hoje?

Sylvia Leser de Mello - Não tenho mais muito contato com essa problemática, mas há uns dois anos o CRP-06 fez um trabalho de recadastramento e me pediu que lesse os dados brutos. Algumas coisas eu achei interessante. Um certo tipo de mudança que me pareceu mais próxima do mundo contemporâneo. Uma delas é que não se fala mais em seleção na área do trabalho. Super. Tem gente trabalhando com sindicato... o perfil é outro. Também achei muito interessante, sem grande análise, pois os dados eram brutos, o fato de um grande número de profissionais, quase a totalidade, estar engajado no que denominavam "área da saúde". Eu achei interessante porque é uma nova maneira de você pensar a clínica, uma perspectiva mais institucional, uma perspectiva mais coletiva, então isso me pareceu um bom sinal. Aparentemente uma nuance, mas não é, pois representa uma mudança. Os psicólogos estão trabalhando, devagarinho vão ganhando espaço nessas chamadas áreas da saúde.

L - E com isso, o psicólogo já não é mais um profissional liberal, mas é...

11 A entrevistadora refere-se ao livro de autoria de Sylvia Leser de Mello, intitulado Psicologia e Profissão em São Paulo. São Paulo, Ática, 1975.
S - ...assalariado. E mais do que isso, porque a perspectiva ideológica do profissional liberal é a perspectiva de um mercado livre, que é a idéia do liberalismo, mas isso vem na contracorrente do liberalismo. As profissões que tinham esse espaço estão sendo confinadas num espaço institucional. Não tem nada a ver com o livre mercado, da livre oferta e da livre procura. Estão num esquema muito mais restritivo, então eu aceito esse emprego, eu faço um concurso, o que configura uma outra cabeça. Eu espero que não seja uma cabeça triste por não ser mais um profissional liberal...

L - Nesse sentido, na medida em que o psicólogo está cada vez mais inserido em instituições, a contribuição da psicologia social talvez possa tornar-se mais evidente, pois aí fica mais clara a necessidade de compreender outros processos, o contexto no qual as pessoas estão.

S - Com certeza. Eu sempre achei que a psicologia social é a psicologia. Eu penso que não dá para você nem sequer intuir como é que o sujeito isolando-o da sociedade, se você não o situa dentro de uma perspectiva social. Sem o social não há sujeito. Dessa forma, a psicologia social deve estar presente desde o começo da formação do aluno de graduação. Ela é fundamental.

L - Ele sempre está em algum lugar. 
S - Em algum lugar e ele vai se definir por esse lugar. $\mathrm{O}$ olhar dele, a postura dele, a forma como ele vai pensar o mundo e o outro, vai ser a partir desse lugar. Agora, se não conheço, se o curso não me dá parâmetros para pensar o sujeito na nossa sociedade, voltamos à filosofia individualista do século XVII. Difícil para você se localizar, mesmo se você for fazer psicologia clínica no velho sentido do consultório. Não se pode perder essa perspectiva de enquadramento e do sujeito que é, por definição, social.

L - Ele está em algum lugar.

S - Ele está em algum lugar. Também eu estou em algum lugar.

L - Como você vê a contribuição da psicologia social para o mundo do trabalho especificamente. De que forma você entende a contribuição da psicologia social para o psicólogo entender o mundo do trabalho.

S - Bom, Leny, eu vou te dar duas respostas. Uma resposta que eu considero antiquada que era a minha perspectiva até alguns anos atrás. É a perspectiva dos sujeitos de um mundo que era definido pelos enquadramentos, uma certa hierarquia que é estabelecida pelo mundo do trabalho. Essa hierarquia você pode estudar em qualquer nicho da vida social. E o trabalho definia o sujeito, dava-lhe o esteio para a sua identidade. Uma identidade adquirida também no trabalho, mas não só no trabalho dele; quer dizer, sartreanamente, não dá para você pensar que o proletário passa a ser proletário, a pensar como proletário a partir do momento em que recebe o primeiro salário, pois ele vem de uma família e de um grupo social, uma classe, em que aqueles possíveis lugares sociais já foram definidos a priori para ele. Então, isso para mim era claro. Hoje, numa sociedade de massa, que é definitivamente a nossa, eu penso que a coisa não funciona mais dessa maneira. Você tem vários tipos de mecanismos funcionando mas quero falar de dois tipos funcionando paralelamente: de um lado as classes médias que ainda se definem muito pela profissão, pela inserção. Veja aquele trabalho sobre funcionários públicos da $A r a k c y{ }^{12}$, no qual aparece aquela inserção específica que lhe dá um status. Eu acho que existe um nível na sociedade em que o trabalho é básico na formação da identidade, é identitário nesse sentido; o sujeito cria laços e relações que tenham a ver com o mundo do trabalho, portanto, o mundo do trabalho se expande para fronteiras que não são mais o trabalho.

Eu acho, porém, que nós estamos convivendo com um outro tipo de problema que eu não sei como definir, que é o do sujeito que não se integra regularmente no mercado de trabalho. Então você tem os que se inserem regularmente, com todo esse processo de significação e identificatório e os que não se inserem e jamais conseguirão se inserir ou nunca "quiseram" efetivamente se inserir nesse mercado. Eu diria que isto configura, também, uma característica da exclusão social, porque esse processo afetou primeiramente aquelas massas mais pauperizadas. Afetou primeiro o sujeito que vem da roça que tinha lá a sua identidade como trabalhador rural, que larga aquilo, vem morar na periferia da cidade, aí ele vai fazer de tudo. Ele vai encontrar a forma possível de sobreviver. Aquela identidade ficou para trás. Ele já não tem uma relação direta com ela. Aqueles que continuam trabalhando como trabalhadores rurais, por exemplo, estou pensando nos bóia-frias, sua ligação

\footnotetext{
12 A entrevistada refere-se ao artigo de Arakcy Martins Rodrigues intitulado: Práticas e representações de pequenos funcionários públicos de São Paulo, publicado na Revista Brasileira de Ciências Sociais, n. 11, vol. 4, outubro de 1989, p. 85-103.
} 
com a terra se empobreceu e não oferece mais suporte identitário enquanto trabalhador rural porque o seu modo de inserção na sociedade se modificou. Eles formam um enorme contingente de trabalhadores que vive nas periferias das cidades, portanto a vida deles não é uma vida rural, é uma vida urbana. Ribeirão Preto me parece modelo dessa espécie de inserção do antigo trabalhador rural. Uma cidade extremamente rica que vive da mão-de-obra dos trabalhadores sazonais. Bom, então, se não encontram mais um lugar claro na sociedade, porque seu trabalho é precário e não insere o trabalhador em qualquer categoria permanente, estamos diante de um problema muito grave. Penso que por isso a questão rural é uma questão premente: possuir um pequeno pedaço de terra, mesmo que seja para viver ainda com mais restrições materiais, significa ser, ter uma identidade possível, localizar-se no espaço social. Além, é claro, do desemprego em massa, claramente uma questão de exclusão social: há uma linha de exclusão que passa por aí. Hoje, você já vê que a classe média também começa a se aproximar dessa linha, também entra nesse esquema de exclusão, com a questão do desemprego. O desemprego é tão apavorante, ele causa uma "pane" tão grande, que ele acaba por ter características de desestruturação e isso repercute na estruturação identitária. Eu acho que há uma linha de exclusão que passa pela questão do trabalho, um trabalho que você faz exclusivamente para ganhar dinheiro. E essa já era a perspectiva do pessoal da Vila Helena ${ }^{13}$. O problema deles não era ter um emprego, mas ter um serviço. Então eles iam, faziam esse serviço, ganhavam pouco. Por exemplo, era uma família que tinha sete, seis rapazes e o pai e nenhum deles estava trabalhando ou trabalhava

13 A entrevistada refere-se ao estudo de sua autoria intitulado Trabalho e sobrevivencia: mulheres do campo e da periferia de São Paulo. São Paulo, Ática, 1988. em bicos ou coisa desse tipo. Mas eles diziam: "nós nunca passamos fome!". Mas ao mesmo tempo configura uma exclusão, porque eles não se educam, a educação passa a ser um acréscimo dispensável. Não há um progresso cultural das massas, embora haja $\mathrm{O}$ progresso material, pois eles constroem suas casas, eles compram carro, compram máquina de lavar etc. Eles são consumidores, mas o progresso cultural é muito mais lento e aparentemente as elites não estão seriamente preocupadas com a educação popular. A cidadania e seu pleno exercício é também um problema cultural, não só de "frango" ou de "dentadura". As massas consomem uma cultura verbal, televisiva. Não lêem jornal, eles lêem revistas, consomem mas é um consumo muito dirigido, um consumo de massa mesmo. Isso só acentua a exclusão. $O$ sujeito está excluído e nunca foi incluído. O sujeito é excluído, ele não está excluído. $\mathrm{Na}$ existência dele, ele é excluído. A sociedade capitalista promove essa exclusão e inclusão. As grandes massas urbanas e rurais nunca estiveram incluídas, sempre estiveram excluídas. Eu acho que o progresso material, se ele não é acompanhado de progresso cultural, eu diria que a gente tem um grande problema social... porque nós vamos criando massas cada vez maiores de sujeitos mal alfabetizados, consumidos pelo consumo, e paradoxalmente sem possibilidade de realizar o consumo. Vão sempre realizar um consumo que é marginal. Você só consegue aprofundar a cidadania se você aprofunda a questão cultural, se você faz a escolarização de um modo mais profundo, se você promove o encontro dessas pessoas com a manifestação cultural e escrita. No filme Terra e Liberdade há um momento em que um personagem, uma camponesa, citando Bakhunin, fala que nós só poderemos construir uma sociedade livre quando todos forem livres. As massas 
acabam por ser muito prontas à manipulação.

L - Você estava falando da exclusão e da identidade. Nesse sentido, se a gente pensar nas práticas mais conhecidas da psicologia na área do trabalho, que são práticas de gestão de recursos humanos, um dos momentos é o de recrutar e selecionar. Então, poderíamos dizer que, na verdade, a psicologia, nessas práticas, exclui as pessoas que já foram excluídas, as pessoas já foram pré-selecionadas pela sociedade.

S - Há um estudo que colhe o depoimento de uma pessoa que trabalha na área de recursos humanos de uma empresa e ela diz muito claramente que eles exigem escolaridade, mas a escolaridade não tem nada a ver com o que as pessoas vão fazer no emprego. Em primeiro lugar, não é mais possível (e diz que deixam muito claro para todos os funcionários), que não há mais passagem da produção para a administração. Não existe mais, há uma linha demarcada muito clara, quer dizer que quem entra na produção fica na produção, quem entrou no escritório está no escritório e tem lá eventualmente possibilidades de melhorar, mas nunca de ascender à chefia. Outra coisa que ela diz, que é impressionante, é que eles fizeram uma reestruturação, o que eles chamam de "racionalização" e mandaram embora um terço dos funcionários e agora ela diz que faz o trabalho de três pessoas... e não ganha mais por isso. E outra coisa que ela diz é que a escolaridade que eles exigem não tem nada a ver com o que eles vão aprender, pois eles vão aprender no trabalho, em três dias eles estão aptos a fazer qualquer coisa lá dentro, mas tem a ver com a sociabilidade. Ela deu a entender que quem anda de chinelo de dedo, de camiseta, esse já está fora. Enfim, é um nível diferente de sociabilidade que exige um maior aprumo na aparência do sujeito. Então, com certeza, muitos já estão excluídos porque não conseguiram aprimorar sequer $\mathrm{O}$ vocabulário, porque continuam falando como aprenderam com suas famílias e nos bairros onde vivem. Eles aprenderam a falar assim. Percebe-se, então, todo um esforço no sentido de melhorar a habilidade lingüística, vestir-se com mais apuro, aprimorar a aparência.

L - E aí, Sylvia, considerando-se esse diagnóstico que você faz, sobre o trabalho, a identidade, a exclusão e inclusão, a impossibilidade de incluir os excluídos, como você acha que a psicologia, preocupada com essas questões do trabalho pode atuar no sentido de iluminar essas questões, ajudar a equacionar esses problemas.

S - Olha, Leny, eu acho que o seu trabalho de doutorado ${ }^{14}$ mostrou muito claramente duas coisas. De um lado a sujeição no trabalho. $\mathrm{O}$ sujeito está ali, o controle sobre ele se dá em minutos, uma coisa impressionante porque essa unidade de tempo praticamente não existe na vida da gente. A análise que o Wright Mills faz sobre a nova classe média, eu acho totalmente válida e até aprofundada, porque o computador é mais alienante, num certo sentido, do que a antiga máquina de escrever. $\mathrm{O}$ escriturário que ficava ali escrevendo com pena, ele ainda sabia o que estava escrevendo, na máquina de escrever isso já vai desaparecendo, mas no computador isso some, desaparece. A Regina ${ }^{15}$ mostra que o sujeito que passa a vida digitando não consegue ler, porque ele não consegue fixar o texto como algo significativo, não consegue ler jornal, ler uma revista.

14 A entrevistada refere-se à tese de doutorado de Leny Sato, intitulado Astúcia e ambigüidade: as condições simbólicas para o replanejamento negociado do trabalho. IPUSP, 1997.

15 A entrevistada refere-se à tese de doutorado de Regina Heloísa Maciel, intitulado Dificuldades de leitura e a tarefa de digitação. IPUSP, 1991, 137p. 
L - Não consegue mais atribuir significado aos signos.

S - A tecnologia tem aprofundado a alienação. Então, eu não acredito que a psicologia tenha muita resposta para dar, mas teria sim que estar atenta a isso que você mostrou, quer dizer, não tratar sujeitos como "recursos humanos"... E isso tem que ser ensinado aos alunos. Essa estória de recursos humanos, infelizmente foi a maneira como a psicologia e a sociologia se encaminharam para pensar a questão do trabalho, porque já começaram a pensar a questão pela perspectiva do capital, do dono da fábrica e não do trabalhador.

Eu acho que isso é um ponto de partida, não é um ponto de chegada. Você deixa isso claro quando você mostra que há um universo prescrito, arrumado, ajeitado, todo "bonitinho" que pode ir para o papel, e há um universo, que é o universo do chão da fábrica, no qual as relações acontecem, do sujeito com a matéria, do sujeito com o sujeito, do sujeito com a máquina.

L - Eles a constroem à revelia desse outro esquema...

S - Dessa prescrição. A prescrição é indicativa, mas não tem aquele nível de realidade que a gerência pensa que ela tem, porque a gerência faz abstração da idéia de que existe um sujeito identitário, para ela o sujeito é tão máquina quanto a máquina.

L - E aí a concepção, que acaba sendo uma ideologia, de que é possível controlar ad infinitum, quando na verdade, óbvio que o controle existe, as pessoas estão submetidas àquela prescrição, mas elas acabam de algum modo conseguindo construir jeitos no sentido de escapar e sobreviver, apesar do controle exercido sobre elas.
S - É, apesar... Isso é o que eu acho a que, a todo instante, o professor de psicologia do trabalho tem que chamar a atenção do aluno. Você não está estudando o trabalhador, está estudando um ser humano que trabalha. Chamar a atenção para isso permanentemente. É evidente que a empresa tem maneiras de envolver, de mostrar que ela está fazendo o melhor possível. E o operário acha que a empresa está fazendo o melhor possível. Como você mostra em seu trabalho: a ambigüidade está presente. Nem o discurso da empresa é coerente e nem o discurso do trabalhador é coerente. São discursos ambíguos, ambos, e nessa ambigüidade os conflitos surgem das mais variadas maneiras, com os mais variados elementos e não são repetitivos porque se fossem repetitivos você tomava conta e punha ordem, organizava, mas são conflitos e modos de ver que surgem diariamente... Isso é fundamental. É a maneira de o aluno eliminar a barreira dos recursos humanos. E aí vão acontecendo outras coisas, entrar com a questão do trabalhador coletivo, com as questões do sindicato. Esta idéia de que ele precisa estar unido para poder negociar, que ele precisa conversar, se sentir representado e ao mesmo tempo se sentir solidário com outros, porque a cidadania passa por isso... A cidadania passa também pela maneira como eu me relaciono com o meu colega de trabalho. Se a cada passo eu puser uma pedra para o outro tropeçar eu estou fazendo o caminho contrário.

Há um outro ponto que deve ser examinado com muito cuidado, mas que apenas poderei apontar aqui. Para nós pesquisadores, que pensamos o trabalho da fábrica a partir do exterior (por mais que teoricamente sejamos solidários e críticos), esse trabalho pode parecer o cúmulo da alienação. É um trabalho "horroroso". É um trabalho "massacrante". Para muitos, porém, a 
fábrica é uma realização, é o ponto de chegada para aqueles que vêm de outros trabalhos ainda mais pesados $\mathrm{e}$ indiferenciados. Se a gente não tem a percepção de que para muitos o trabalho na fábrica é o ponto de chegada e é o progresso na vida deles, a gente também não está enxergando nada.

L - Esse aspecto que você está levantando é importante, porque a psicologia, justamente por ter subsídios para compreender que existem vários mundos, ela tem que contemplar essas diferenças de valores, de visões, conseguir compreender que é ponto de chegada, que não é humilhação...

S - A fábrica é ponto de chegada porque sai da humilhação do trabalho doméstico. Eu vejo isso com clareza na Vila Helena. As mulheres são empregadas domésticas e algumas têm todos os direitos. E os filhos não querem saber disso, nenhuma das meninas aceita passar pelo serviço doméstico. Elas ficam desempregadas mas elas querem a fábrica, um outro tipo de serviço. Eu acho isso muito positivo porque, apesar de tudo, o serviço doméstico está muito próximo daquela coisa meio indiscriminada do escravo, do sujeito doméstico que está lá...

L - ...disponível...

S - É. Eu acho isso muito positivo. E é muito positivo que muitas meninas que vão para a fábrica adquiram um discurso, dependendo do sindicato, um discurso político. Isso é muito interessante. A identidade delas vai se formando e é uma identidade ligada ao trabalho, ligada à condição de trabalhadora de fábrica, ligada àquela condição do trabalho de fábrica. Mesmo aquelas mulheres mais velhas que foram trabalhar em fábrica não têm retorno. Elas não aceitariam mais o trabalho doméstico. Se bem que há empregadas domésticas que ganham bem mais do que a operária.

Há mais um aspecto do trabalho que acho importante. Eu sempre achei, e no caso das mulheres isso é evidente, que a autonomia financeira dada pelo trabalho é extremamente positiva, sobretudo com os maridos. Você estabelece um patamar de igualdade que é fundamental. Inibe um pouco a violência. E coloca você numa base de igualdade quando você vai lidar com os seus filhos. Os seus filhos respeitam você como uma pessoa que contribui, que sabe o que é o trabalho. Eu sempre achei que isso funciona muito atrelado à idéia de salário, mas eu não sei como isso funciona quando atrelado a esse emprego eventual.

L - Voltando um pouco, nós estamos falando que "gente é gente", que não dá para transformar as pessoas em recursos humanos. Como você vê a possibilidade de a psicologia, ao atuar nas organizações, responder a demandas gerenciais, tanto de modificar comportamentos, como de criar habilidades técnicas? Será que de fato ela consegue responder a essas demandas, na medida em que os trabalhadores criam outros modos de realizar as prescrições, na medida em que buscam manter sua humanidade?

S - Qual é o papel de psicologia... Talvez o papel da gente numa empresa, seja exatamente esse, de mostrar que as pessoas mantêm-se como pessoas. Não sei se isso é possível, não sei qual é o espaço do psicólogo dentro da empresa. Ele também está submetido a tudo isso. Ele também é tratado como um recurso humano. O psicólogo não é nem da alta gerência e nem é o trabalhador que põe a mão na massa. Não é uma posição tranqüila. Mas ele não pode perder a perspectiva de que ele está nessa posição. Um aluno que estagiou no Japão ficou 
perplexo diante da profunda ambigüidade que marca as relações de trabalho, quando se valoriza o trabalhador e em algumas situações ele é tratado como autômato.

L - Você está falando do Japão e me fez lembrar como no Brasil, nessa área de recursos humanos, observa-se, como em outras, a concepção de que é possível transpor modelos de gestão, como se fossem técnicas, e se você não vê que as pessoas não são recursos humanos, você acha que é possível transpor modelos.

$\mathrm{S}$ - É impossível transpor modelos. Inclusive porque você esbarra com o tipo de formação. Culturalmente os valores que estruturam nossa psique são diferentes. A organização da sociedade difere de região para região.

L - No seu contato com os alunos de graduação, como você vê a preocupação deles com a questão do trabalho?

S - A experiência ${ }^{16}$ que nós incluímos, que o Moura ${ }^{17}$ introduziu, foi interessante porque os alunos começam a perceber as situações de trabalho, eles começam a se colocar no lugar do outro. Essa experiência tem funcionado muito como um despertar para a realidade que não é a deles e o reconhecimento do outro nessa realidade. Perceber o ser humano vivendo uma vida totalmente diferente da sua e tão real quanto a sua.

L - Eu acho importante propiciar essa vivência, trazer essa dimensão do trabalho em uma disciplina que não é a que, teoricamente, vai cuidar do trabalho, como psicologia do trabalho, seleção profissional, pois isso traz para o

16 A experiência referida pela entrevistada consiste em solicitar aos alunos de psicologia matriculados na disciplina Psicologia Social II que vivenciem um dia de trabalho exercendo uma função subalterna.

17 Professor José Moura Gonçalves Filho, Instituto de Psicologia da USP. aluno uma concepção dentro da psicologia de que o trabalho não é uma área de atuação, mas...

S - É central, é nuclear.

L - E aí tem essa série de coisas que você estava falando, da identidade, da inclusão, da exclusão social... 